\title{
Prevention of Leaks and Strictures of Esophago-Organ Anastomosis in Esophagoplasty
}

Research Article

Shaprynskyi $\mathrm{VO}^{1}$, Shaprynskyi $\mathrm{YV}^{2 *}$, Hussein $\mathrm{MB}^{3}$

${ }^{1}$ Professor, Doctor of Medicine, Head of Surgery Department No 1, National Pirogov Memorial Medical University, Vinnytsia, Ukraine.

${ }^{2}$ Doctor of Medicine, Associate Professor of Surgery Department, Medical Faculty No 2, National Pirogov Memorial Medical University, Vinnytsia, Ukraine.

${ }^{3}$ Post-Graduate Student, Surgery Department No 1, National Pirogov Memorial Medical University, Vinnytsia, Ukraine.

\section{Abstract}

Notwithstanding modern achievements in reconstructive surgery of the esophagus, intensive care, progress in modern clinical pharmacology, anesthesiology and reanimation, the results of such operations are still considered unsatisfactory. One of the most severe complications leading to the development of postoperative empyema and sepsis is anastomotic leakage, occurring in $9 \%-17 \%$ of cases. In long-term postoperative periodthe leaks lead to the development of esophago-organ anastomotic strictures, requiring repeated restorative interventions.

The aim of the work was to decrease the incidence of leaks and strictures of esophago-organ anastomosis in esophagoplasty by predicting the risk of their occurrence and using the developed method of anastomosis formation.

116 patients with esophageal strictures were included in the study: 45 patients had post-burn strictures, 10-peptic strictures, 17-postoperative strictures and 44 patients -esophageal cancer. The most significant predictors of postoperative complications were identified by modeling the risk of their development using logistic regression method. In experimental group of patients, an individual approach to the choice of surgical intervention method was applied using an improved diagnostic and treatment algorithm with prediction of complication risk, the developed instrumental method of esophago-organ anastomosis creation.

The results of operative treatment for esophageal strictures showed early post-operative complications to develop in 60 patients $(51.72 \%)$. There were six deaths: four patients in the control group and two patients - in experimental group.

The use of diagnostic and treatment algorithm with prediction of complication risk, the developed method for creation of esophago-organ anastomosis was associated with steady postoperative improvement in general clinical and laboratory parameters. Leaks and strictures of cervical esophago-organ anastomosis occurred in 7 patients $(11.48 \%)$ of experimental group and 15 patients $(27.27 \%)$ of the control group $(\mathrm{p}<0.05)$.

Keywords: Anastomotic Leak; Corrosive Stricture; Treatment Algorithm; Anastomosis.

\section{Introduction}

Notwithstanding modern achievements in reconstructive surgery of the esophagus, intensive care, progress in modern clinical pharmacology, anesthesiology and reanimation, which have extended indications for radical operations, their results are still unsatisfactory $[1,2]$. According to many authors, complications in postoperative period after resection, esophageal extirpation and reconstructive operations on the esophagus occur in $19-25 \%$ of patients.

One of the most severe complications leading to the development of postoperative empyema and sepsis is anastomotic leak, occurring in 9\%-17\% of cases. In long-term postoperative period

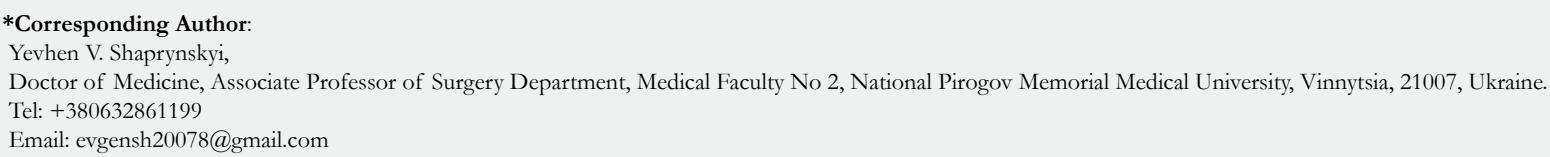

Received: August 22, 2019

Accepted: October 15, 2019

Published: October 17, 2019

Citation: Shaprynskyi VO, Shaprynskyi YV, Hussein MB. Prevention of Leaks and Strictures of Esophago-Organ Anastomosis in Esophagoplasty. Int J Surg Res. 2019;6(2):132 135. doi: http://dx.doi.org/10.19070/2379-156X-1900028

Copyright: Yevhen V. Shaprynskyi ${ }^{\circ}$ 2019. This is an open-access article distributed under the terms of the Creative Commons Attribution License, which permits unrestricted use, distribution and reproduction in any medium, provided the original author and source are credited. 
they result in strictures of esophago-organ anastomosis, requiring repeated restorative interventions [3, 4]. Postoperative death rate associated with leakage of esophago-organ anastomosis reaches $70 \%$, and no significant tendency to its decrease is observed $[5,6]$.

Numerous studies, presented in modern scientific literature, are devoted to various methods of preventing the leakage of hollow organs anastomoses, but unfortunately, the problem of anastomotic leakage is still urgent in surgery [7-9]. There are studies on techniques of esophago-organ anastomosisformation, the state of transplant microcirculation at the site of potential anastomosis, the degree of bacterial contamination in suprastenotic portion of the esophagus before and after surgery, tissue regeneration in the fistula region $[10,11]$. Little attention is paid to the method of prognosis of this complication development. In addition, those complications often occur after reconstructive surgery on the esophagus in elderly and senile patients, having usually concomitant pathology. Severe concomitant conditions interfere with normal compensation processes, slow down the dynamics of recovery of the patient's functional state, resulting in sharply decreased regenerative processes throughout the body in early postoperative period, especially in the region of anastomosis and postoperative wound $[12,14]$.

The aim of the work was to decrease the incidence of leaks and strictures of esophago-organ anastomoses in operative treatment of esophageal strictures by predicting the risk of their development and improvement of anastomosis creation technique.

\section{Materials and Methods}

116 patients with esophageal strictures were included in the study. The patients were treated at the Department of esophageal and gastro-intestinal diseases of state institution "V.T.Zaitsev Institute of General and Emergency Surgery of National Academy of Medical Sciences" (70 individuals) and Thoracic Surgery Department of Vinnytsya Regional Pirogov Memorial Clinical Hospital (46 patients) during the period of 2005-2018.

By etiology the esophageal strictures were divided into post-burn in 45 patients, peptic strictures (associated with reflux esophagitis) - in 10, postoperative - in 17, and tumor diseases of the esophagus presented by esophageal cancer - in 44 patients. Distribution by age showed the mean age to be 34 years. The great majority of patients were 21-60 years old, i.e. working-age individuals. There were 79 men aged 20-66,average age 30.5 years, and 37 women aged $18-70$, average age 36 years. Hospitalized patients $(85.34 \%)$ with benign esophageal strictures had the third and fourth degree of esophageal obstruction.

Patients with esophageal strictures were divided into two groups: control group, consisting of 55 patients (47.41\%) and experimental group, involving 61 patients $(52.59 \%)$. The patients of the control group underwent conventional surgical treatment of corrosive esophageal strictures according to existing protocols and standards. In experimental group of patients, an individual approach to the choice of surgical intervention method was applied using an improved diagnostic and treatment algorithm with prediction of complication risk, as well as the developed instrumental method of esophago-organ anastomosis formation.
Conventional examinations included estimation of the risk of complication development. Logistic regression method was used to evaluate the role of certain factors in esophageal anastomotic leakage development after esophagoplasty according to unmatched case-control unbalanced design of the study. A total of 100 patients were studied, 52 of them had complications and 48 developed no complications (controls). The most significant predictors of postoperative complications were identified by modeling the risk of their development. By coefficient values, the risk of cervical esophago-organ anastomotic leakage and associated complications was found to be increased in anemia, model coefficient $=2.0629, \mathrm{p}=0.0356$; decreased albumin level- less than $25 \mathrm{~g} / \mathrm{l}$, model coefficient $=2.9323, \mathrm{p}=0.0117$; diabetes mellitus, model coefficient $=3.1555, \mathrm{p}=0.0156$; total esophageal obstruction, model coefficient $=2.9962, \mathrm{p}=0.0104$. Application of the proposed instrumental method for cervical anastomosis formation significantly reduced the risk of its leakage, model coefficient $=-6.4835, \mathrm{p}=0.0068$. When comparing informative value of full and reduced models, no significant differences were found, (chisquared 7) $=5 ; \mathrm{p}=0.3300)$. Thus, the two models had similar prognostic value. As linear predictorconsists of only five risk factors, the range of predicted risk of leakage development is wide - from $0 \%$ to $99.8 \%$.

According to the above mentioned estimates, the prognostic model is as follows:

$$
r=\{1+\exp (- \text { regpred })\}^{-1}
$$

where $r$ - prognostic risk of cervical esophago-organ anastomotic leakage, exp-exponent, regpred - regression predictor variable,

regpred $=-6.1224+2.0629 *$ anemia $+2.9323 *$ hypoproteinemia $+3.1655 *$ diabetes mellitus $+2.9962 *$ total esophageal obstruction $-6.4835^{*}$ application of suggested method of anastomosis formation.

\section{Results and Discussion}

Treatment algorithm consisted of predicting the risk of complications, and if it exceeded $70 \%$, the patients were not operated on. They underwent intensive therapy in the intensive care unit to correct metabolic disorders, and stenting of the stricture region with nitinol stents if possible. In other cases gastrostomy by Witzel's method or Kader procedure were performed. When prognostic risk of cervical esophago-organ anastomotic leakage was $40-70 \%$, the patients underwent correction of concomitant pathology and protein and water-electrolyte metabolism in intensive care unit to be prepared for reconstructive surgery. When anastomotic leakage risk was less than $40 \%$, the patients underwent reconstructive surgery after proper preoperative preparation in the surgical department.

The developed instrumental method for the formation of esophago-organ anastomosis was used in 7 patients (useful model patent of Ukraine № 132523 of 25.02.2019). According to this method, during esophageal reconstructive procedure, after formation of the transplant and its placement on the neck area (through the posterior mediastinum in plastics with gastric tube or retrosternal plastics of the esophagus with the colon), the removable head of the circular stapler is fixed in the remnant of the esophagus and 
purse-string-type closure is performed. For anastomosis creation, the circular stapler $\mathrm{CH} 29$ is inserted through the proximal portion of the transplant in the neck region, and end-to-side mechanical anastomosis is formed (Figure 1). After mechanical suturing, circular stapler is opened and extracted from the corresponding organlumens. Then, gastric tube No 18 is inserted through the created mechanical anastomosis. Mechanical suture line is reinforced by quilted sutures, beginning and ending on the transplant at a distance of $1 \mathrm{~cm}$ from the line of instrumental anastomosis. First, all sutures are placed, and then they are tiedin turn, thus placing the esophageal stump in the graft (Figure 2, Figure 3). After formation of anastomosis, the excessive part of the transplant (gastric tube or colon) is cut off with a linear stapler.
The results of surgical treatment in patients with corrosive esophageal strictures showed the development of early postoperative complications in 60 individuals $(51.72 \%)$. There were six deaths: four - in the control group and two - in experimental group. In experimental group, where diagnostic and treatment algorithm with prognostic risk of complications and the developed method for creation of esophago-organ anastomosis were used, the patients demonstrated steady improvement of postoperative general clinical and laboratory indices. Leakage of cervical esophago-organ anastomosis and esophageal strictures occurred in 7 patients (11.48\%) of experimental group and 15 patients $(27.27 \%)$ of the control group $(\mathrm{p}<0.05)$.

The use of prognostic risk model for complication developmen-

Figure 1. Formation of Mechanical End-to-Side Anastomosis.

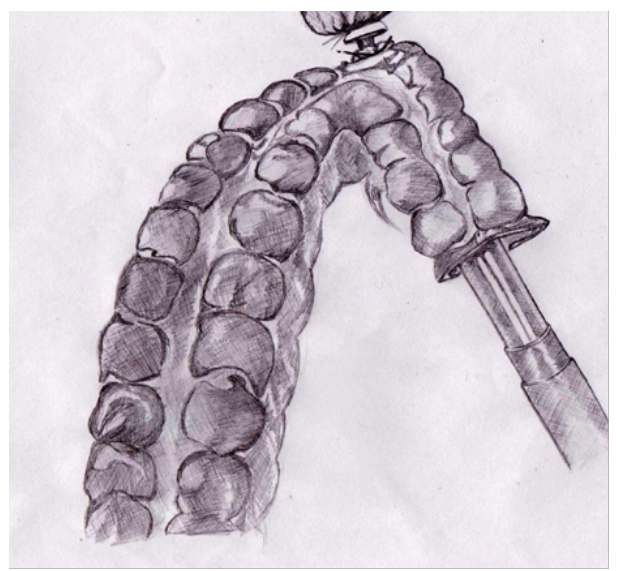

Figure 2. Reinforcement of Mechanical Suture Line with Quilted Sutures.

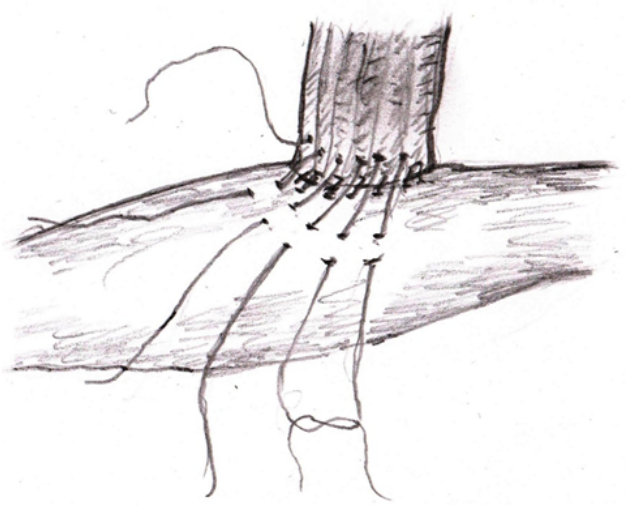

Figure 3. Invagination of Esophageal Stump in the Transplant.

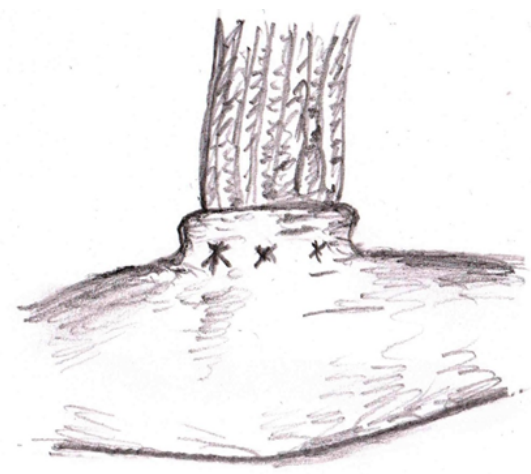


tassociated with cervical anastomosis, the proposed therapeutic algorithm, as well as the developed method of circular staple cervical anastomosis creation resulted in reduced incidence of leaks and strictures of esophago-organ anastomosis; decreased time of hospitalization - from $28.2 \pm 1.1$ to $21.5 \pm 0.5$ bed-days ( $\mathrm{p}$ $<0.001$ ), postoperative period - from $20.5 \pm 1.1$ to $16.1 \pm 0.7$ beddays ( $\mathrm{p}<0.01$ ); decreased postoperative mortality - from $7.27 \%$ to $3.28 \%$

\section{Conclusion}

The use of diagnostic algorithm including prognostic risk model for complications, the developed optimal therapeutic approach as well as the developed instrumental anastomosis was associate with significantly lower incidence of esophago-organ anastomotic complications, steady improvement of postoperative clinical and laboratory parameters, lower mortality rate.

The proposed method of anastomosis creation can be used in gastrictube esophagoplasty or esophagoplasty with colonic segment to form esophago gastric and esophago colonic anastomosis in the cervical region. Besides, this type of anastomosis creationis associated with high leak resistance and minimal risk of anastomotic leakage.

\section{References}

[1]. Thomas N. With minimally invasive esophagectomy, thoracic surgeons must avoid falling into the same trap again! Semin Thorac Cardiovasc Surg. 2015 Summer; 27(2):216-7. PubMed PMID: 26686449.

[2]. Mariette C, Meunier B, Pezet D, Dalban C, Collet D, Thomas PA, Brigand C, Perniceni T, Carrere N, Bonnetain F, Piessen G. Hybrid minimally invasive versus open oesophagectomy for patients with oesophageal cancer: A multicenter, open-label, randomized phase III controlled trial, the MIRO trial. J Clin Oncol. 2015; 33.
[3]. Korst RJ, Port JL, Lee PC, Altorki NK. Intrathoracic manifestations of cervical anastomotic leaks after transthoracic esophagectomy for carcinoma. Ann Thorac Surg. 2005 Oct;80(4):1185-90. PubMed PMID: 16181838.

[4]. van Heijl M, van Wijngaarden AK, Lagarde SM, Busch OR, van Lanschot JJ, van Berge Henegouwen MI. Intrathoracic manifestations of cervical anastomotic leaks after transhiatal and transthoracic oesophagectomy. $\mathrm{Br} \mathrm{J}$ Surg. 2010 May;97(5):726-31. PubMed PMID: 20235083.

[5]. Finks JF, Osborne NH, Birkmeyer JD. Trends in hospital volume and operative mortality for high-risk surgery. N Engl J Med. 2011 Jun 2;364(22):2128-37. PubMed PMID: 21631325.

[6]. Talsma AK, Lingsma HF, Steyerberg EW, Wijnhoven BP, Van Lanschot JJ. The 30-day versus in-hospital and 90-day mortality after esophagectomy as indicators for quality of care. Ann Surg. 2014 Aug;260(2):267-73. PubMed PMID: 25350650.

[7]. Markar SR, Arya S, Karthikesalingam A, Hanna GB. Technical factors that affect anastomotic integrity following esophagectomy: systematic review and meta-analysis. Ann Surg Oncol. 2013 Dec;20(13):4274-81. PubMed PMID: 23943033.

[8]. Biere SS, Maas KW, Cuesta MA, van der Peet DL. Cervical or thoracic anastomosis after esophagectomy for cancer: a systematic review and metaanalysis. Dig Surg. 2011;28(1):29-35. PubMed PMID: 21293129.

[9]. Irino T, Tsai JA, Ericson J, et al. Thoracoscopic side-to-side esophagogastrostomy by use of linear stapler - a simplified technique facilitating a minimally invasive Ivor-Lewis operation. Langenbecks Arch Surg. 2016 May;401(3):315-22. PubMed PMID: 26960591.

[10]. ShaprynskyiV. O., ShaprinskiyY. V., KaryiY. V.,et al. Operative treatment of corrosive esophageal strictures. Wiad Lek. 2018;71(2 pt 2):323-325. PubMed PMID: 29786579.

[11]. Blencowe NS, Strong S, McNair AG, et al. Reporting of short-term clinical outcomes after esophagectomy: a systematic review. Ann Surg. 2012 Apr;255(4):658-66. PubMed PMID: 22395090.

[12]. Low DE, Alderson D, Cecconello I, et al. International Consensus on Standardization of Data Collection for Complications Associated with Esophagectomy: Esophagectomy Complications Consensus Group (ECCG). Ann Surg. 2015 Aug;262(2):286-94. PubMed PMID: 25607756.

[13]. Straatman J, van der Wielen N, Cuesta MA, et al. Minimally invasive versus open esophagectomy resection. Three-year follow-up of the previously reported randomized controlled trial: the TIME trial. Ann Surg. 2017 Aug;266(2):232-236. PubMed PMID: 28187044.

[14]. Wei B, D’Amico TA. Thoracoscopic versus robotic approaches: advantages and disadvantages. Thorac Surg Clin. 2014 May;24(2):177-88. PubMed PMID: 24780422. 